\title{
A novel mutation in DAX1 causes delayed-onset adrenal insufficiency and incomplete hypogonadotropic hypogonadism
}

\author{
Antoine Tabarin, ${ }^{1}$ John C. Achermann, ${ }^{2}$ Dominique Recan, ${ }^{3}$ Véronique Bex, ${ }^{1}$ \\ Xavier Bertagna, ${ }^{4}$ Sophie Christin-Maitre, ${ }^{5}$ Masafumi Ito, ${ }^{2}$ J. Larry Jameson, ${ }^{2}$ \\ and Philippe Bouchard ${ }^{5}$
}
${ }^{1}$ Département d'Endocrinologie, Diabétologie du CHU de Bordeaux, USN Haut Levêque, 33604 Pessac, France 2Division of Endocrinology, Metabolism, and Molecular Medicine, Northwestern University Medical School, Chicago, Illinois 60611, USA
${ }^{3}$ Service de Biochimie et Génétique Moléculaire, and
${ }^{4}$ Service d'Endocrinologie, Hôpital Cochin, 75014 Paris, France
${ }^{5}$ Service d'Endocrinologie et Maladies de la Reproduction, Hôpital Saint-Antoine, 75012 Paris, France

Address correspondence to: A. Tabarin, Département d'Endocrinologie, Diabétologie du CHU de Bordeaux, USN Haut Levêque, Ave Magellan, 33604 Pessac, France.

Phone: 33-5-56-55-64-24; Fax: 33-5-56-55-68-06; E-mail: antoine.tabarin@chu-aquitaine.fr.

Received for publication April 29, 1999, and accepted for publication December 14, 1999.

\begin{abstract}
Mutations in the DAX1 gene cause X-linked adrenal hypoplasia congenita (AHC) and hypogonadotropic hypogonadism (HHG). In affected boys, primary adrenal insufficiency occurs soon after birth or during early childhood; HHG is recognized at the expected time of puberty. In this report, we describe the novel phenotype of a man who presented with apparently isolated adrenal insufficiency at 28 years of age. Examination revealed partial pubertal development and undiagnosed incomplete HHG. Gonadotropin therapy did not improve his marked oligospermia, suggesting a concomitant primary testicular abnormality. Genomic analysis revealed a novel missense mutation, I439S, in DAX1. The mutant DAX-1 protein was studied for its ability to function as a transcriptional repressor of target genes. Consistent with the patient's mild clinical phenotype, the I439S mutation conferred intermediate levels of repressor activity of DAX-1 when compared with mutations associated with classic AHC. This unique case extends the clinical spectrum of AHC to include delayed-onset primary adrenal insufficiency in adulthood and milder forms of HHG. Furthermore, in accordance with findings in $A b c h$ (Dax1) knockout mice, the clinical features in this patient suggest that DAX-1 function is required for spermatogenesis in humans, independent of its known effects on gonadotropin production.
\end{abstract}

J. Clin. Invest. 105:321-328 (2000)

\section{Introduction}

The DAX1 gene encodes an orphan member of the nuclear receptor superfamily that lacks the typical zinc finger DNA-binding motif, but retains the ligand-binding domain characteristic of other family members (1). DAX-1 is expressed in the adrenal cortex, gonads, hypothalamus and anterior pituitary (2). It interacts with another orphan nuclear receptor, steroidogenic factor-1 (SF-1) (3), which plays a pivotal role in the development and function of these tissues (4-9). In vitro studies suggest that DAX-1 represses SF-1-mediated transcription, but the roles of SF-1 and DAX-1 in the development and function of these tissues remain unclear (5-7). Recent results obtained in $A b c h$ (the mouse Dax 1 homologue) knockout mice suggest that DAX-1 may also play a direct role in spermatogenesis (10).

Mutations in the DAX1 gene in humans cause the Xlinked cytomegalic form of adrenal hypoplasia congenita (AHC), a rare disorder characterized by impaired development of the permanent zone of the adrenal cor- tex and hypogonadotropic hypogonadism (HHG) (1, 11). Affected boys develop adrenal failure shortly after birth or during early childhood, whereas HHG, a universal feature of the syndrome, is usually recognized at the expected time of puberty $(9,12,13)$. Whether or not DAX1 mutations affect spermatogenesis in humans, independent of the effects of gonadotropin deficiency, remains unknown (9).

In this report, we describe the clinical features of a patient with a mild phenotypic presentation of AHC and examine the functional properties of the mutant DAX-1 protein. In addition, we describe the results of exogenous gonadotropin therapy on spermatogenesis. Recognition of this unique phenotype is of practical importance because it extends the clinical spectrum of the disease to include mild forms of HHG and delayed onset of adrenal insufficiency. Studies in this patient also suggest that DAX-1 function is required for spermatogenesis in humans, independent of gonadotropin and testosterone production. 


\section{Methods}

Hormone assays and pulse analysis. Follicle-stimulating hormone (FSH) and luteinizing hormone (LH) were measured using chemiluminescent immunoassays (Chiron Diagnostics, Cergy-Pontoise, France). The FSH and LH assays had an analytical sensitivity of $0.3 \mathrm{IU} / \mathrm{L}$ and $0.07 \mathrm{IU} / \mathrm{L}$, respectively. The intra- and interassay coefficients of variation were, respectively, $2.8 \%$ and $4.6 \%$ at $4 \mathrm{IU} / \mathrm{L}$ for $\mathrm{FSH}$, and $4.7 \%$ and $6.3 \%$ at $5 \mathrm{IU} / \mathrm{L}$ for LH. Free $\alpha$ subunit (FAS) was measured using an immunoradiometric assay (Immunotech, Marseilles, France). The FAS assay had an analytical sensitivity of $0.02 \mathrm{IU} / \mathrm{L}$. The intra- and interassay coefficients of variation were $6.8 \%$ and $8.6 \%$ at $0.44 \mathrm{IU} / \mathrm{L}$. Serum inhibin B was measured as described previously (14). LH and FAS pulsatility was determined using cluster analysis (method number 7$)(15)$.

DNA sequencing and mutation analysis. Genomic DNA was extracted from peripheral blood leukocytes using standard procedures. The gonadotropin-releasing hormone $(\mathrm{GnRH})$ receptor gene was sequenced as described previously (16). Exons 1 and 2 of $D A X 1$ were PCR-amplified with specific primers as described previously (11). The following primer pair was used to amplify and sequence exon 2: 2F (sense): $5^{\prime}$-GCTAGCAAAGGACTCTGTGGTG-3' and 2R (antisense): $5^{\prime}$-CCCTCATGGTGAACTGCACTAC-3'. PCR was performed in 50$\mu \mathrm{L}$ volumes containing $200 \mathrm{ng}$ of genomic DNA, 50 pM of each dNTP, 10 pmol each of primer (2F and $2 \mathrm{R}$ ),

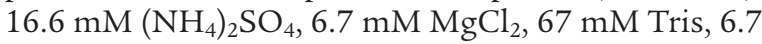
$\mu \mathrm{M}$ EDTA, $1 \%$ DMSO, and 0.4 units of Taq-I polymerase (Roche Diagnostics, Meylan, France). PCR conditions were 30 cycles as follows: 30 seconds at $96^{\circ} \mathrm{C}$, 90 seconds at $60.5^{\circ} \mathrm{C}$, and 2 minutes at $72^{\circ} \mathrm{C}$. This sequence was followed by a final extension step at $72^{\circ} \mathrm{C}$ for 7 minutes. PCR products were run on a $1.5 \%$ NuSieve gel. Purified PCR products (50 ng) were sequenced directly using the Taq Big Dye Terminator sequencing kit (Perkin-Elmer Applied Biosystems, Foster City, California, USA) with primers $2 \mathrm{~F}$ and $2 \mathrm{R}$. After identification of the mutation by DNA sequencing, $B s r D I$ restriction digestion was used to detect the mutation in additional family members. Restriction enzyme digestions using $B s r D I$ were performed at $60^{\circ} \mathrm{C}$ in a 30 $\mu \mathrm{L}$ reaction mixture containing $15 \mu \mathrm{L}$ of PCR product 2F/2R, 20 U BsrDI (New England Biolabs, Beverly, Massachusetts, USA), $3 \mu \mathrm{L}$ NE buffer, and $0.3 \mu \mathrm{L}$ BSA (all supplied by the manufacturer). The DNA digestion products were run on a $6 \%$ acrylamide gel.

Construction of DAX-1 expression vectors. DAX $1 \mathrm{cDNA}$ containing the patient's I439S mutation was created by site-directed mutagenesis using full-length human $D A X 1$ cDNA as a template and an overlapping PCR strategy with primers containing the appropriate nucleotide substitutions (A $\underline{T C}$ to $\mathrm{A} \underline{\mathrm{G}}$ ). A similar overlapping PCR approach was used to create mutant cDNA fragments containing the other naturally occurring DAX-1 mutations, R267P and $\Delta \mathrm{V} 269$ (6, 11). A carboxy terminal deletion mutant of DAX-1
$(\Delta 448-470)$ was made by restriction enzyme digestion of wild-type cDNA (6). Each mutant DNA fragment was inserted into wild-type DAX1 cDNA using appropriate restriction enzyme sites. Mutations were verified by direct DNA sequencing.

Full-length wild-type or mutant (R267P, $\Delta$ V269, I439S, and $\triangle 448-470) D A X 1$ cDNA was introduced into a PCMX vector to allow expression of full-length wild-type or mutant DAX-1 protein. In addition, cDNA corresponding to the putative ligand-binding (LBD) domain of DAX-1 alone (codons 207-470) was introduced into a $\mathrm{pBIND}$ vector (Promega Corp., Madison, Wisconsin, USA) and linked to a GAL4 DNA-binding domain (DBD) to allow expression of wild-type and mutant GAL4-DAX-1 fusion proteins.

Construction of SF-1 and Egr-1 expression vectors and reporter genes. Human SF1 (FTZF1) cDNA (kindly provided by M.S. Ramayya, University of Washington, Seattle, Washington, USA) was introduced into a pCMX vector to express full-length SF-1 protein. In addition, cDNA corresponding to the transcriptional activation domain of SF-1 (codons 133-461) was introduced into a PBIND vector and linked to the GAL4 DBD to express a GAL4-SF-1 fusion protein (6). Rat early growth response 1 (Egr1) cDNA was introduced into a $\mathrm{PCMX}$ vector for expression of fulllength Egr-1 protein (17).

The UAS-TK109luc reporter was used for GAL4 fusion protein studies, as described previously (6). This reporter contains 2 GAL4 binding sites (UAS) upstream of the -109 TK promoter. A rat LH $\beta$ gene reporter containing nucleotides -154 to +5 of the LH $\beta$ gene promoter was inserted into a pA3 luciferase vector.

Transient gene expression studies. Transient gene expression studies were performed using a human embryonic kidney tsa201 cell line (18). These cells were grown in DMEM supplemented with $10 \%$ FBS, $1 \%$ penicillin, and $1 \%$ streptomycin in a $5 \% \mathrm{CO}_{2}$ atmosphere at $37^{\circ} \mathrm{C}$.

The effect of DAX-1 and its mutants on basal transcriptional activity was investigated by cotransfecting 25 ng pBINDGAL4-DAX-1 expression vector (empty, hDAX1 wild-type, R267P, $\Delta \mathrm{V} 269$, I439S, or $\Delta 448-470)$ with 500 ng UAS-TK109luc reporter (6). The effect of DAX-1 and its mutants on SF-1 mediated transactivation was investigated by cotransfecting $50 \mathrm{ng}$ PCMX-DAX-1 expression vector with 25 ng pBINDGAL4-SF-1 and 500 ng UAS-TK109luc reporter. The effect of DAX-1 and its mutants on the synergistic activation of the native rat $\mathrm{LH} \beta$ gene promoter by SF- 1 and Egr-1 was investigated by cotransfecting $50 \mathrm{ng}$ pCMX-DAX-1 expression vector with $20 \mathrm{ng}$ pCMX-SF-1, 20 ng pCMX-Egr-1, and 500 ng pA3LH $\beta$ gene reporter.

All transfections were performed in triplicate, using calcium phosphate precipitation. Cell extracts were prepared 48 hours after transfection, and luciferase assays were performed. The mean of each triplicate reaction was expressed as a percentage of 


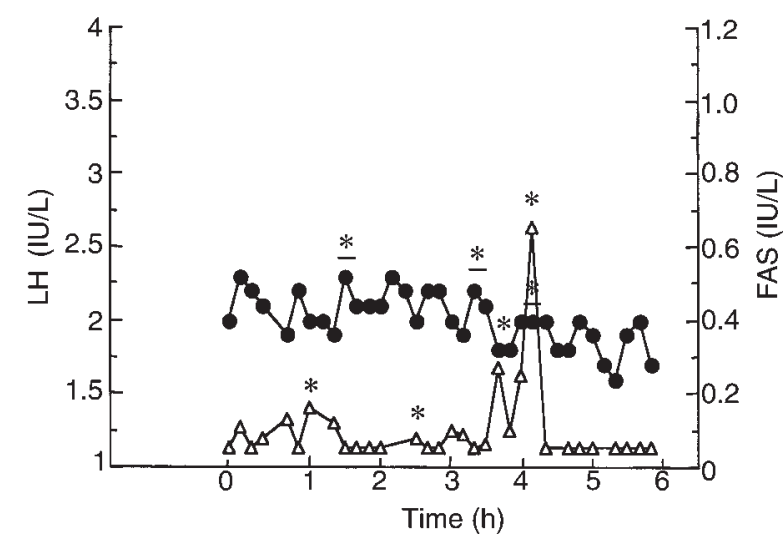

Figure 1

Endogenous LH (filled circles) and FAS (open triangles) determination at 10-minute intervals for 6 hours. Asterisks and underlined asterisks denote FAS and $\mathrm{LH}$ pulses, respectively.

the DAX-1 empty vector control for that study to allow comparison of data from different experiments. The results represent the mean \pm SEM from at least 6 independent experiments, each consisting of triplicate transfections.

\section{Results}

Case report. A 28-year-old man was referred with suspected adrenocortical failure. He complained of fatigue for 5 years. Evaluation performed by his general practitioner 4 years before presentation revealed low 24-hour urinary excretion of 17 -hydroxycorticosteroids and 17-ketosteroids $(2.3 \mathrm{mg} / \mathrm{d}$ and $5.7 \mathrm{mg} / \mathrm{d}$; normal range: $4-8 \mathrm{mg} / \mathrm{d}$ and $12-18 \mathrm{mg} / \mathrm{d}$, respectively). However, no diagnosis was made at that time, nor was any medication given. During the year before admission, the patient noted additional symptoms such as episodes of nausea, abdominal pain, orthostatic dizziness, and the loss of $4.5 \mathrm{~kg}$ of body weight. His height and weight were $171 \mathrm{~cm}$ and $58 \mathrm{~kg}$, respectively, and his blood pressure was $100 / 60 \mathrm{mmHg}$ while supine. On physical examination, moderate and diffuse increased skin pigmentation was noted, with a few hyperpigmented macules on the lips.

Baseline sodium was low $(133 \mathrm{mmol} / \mathrm{L}$; normal: 135-145 mmol/L), potassium was increased (6.0 $\mathrm{mmol} / \mathrm{L}$; normal: $3.5-5.0 \mathrm{mmol} / \mathrm{L}$ ) and blood glucose was normal. The diagnosis of primary adrenal insufficiency was made in view of an elevated 800-hour serum adrenocorticotropic hormone concentration (60 pmol/L; normal: < $10 \mathrm{pmol} / \mathrm{L}$ ) associated with a low cortisol concentration $(63 \mathrm{nmol} / \mathrm{L}$; normal range: 193-690 nmol/L), which did not increase after cosyntropin stimulation $(250 \mu \mathrm{g}$ intramuscularly). Serum aldosterone was undetectable, whereas supine and plasma renin activity was dramatically increased $(29 \mathrm{ng} / \mathrm{mL}$ per hour; normal range: $0.16-2.3 \mathrm{ng} / \mathrm{mL}$ per hour). The serum concentrations of dehydroepiandrosterone sulfate $(0.4 \mu \mathrm{mol} / \mathrm{L})$ and 17-hydroxyprogesterone (0.6 $\mathrm{nmol} / \mathrm{L}$ ) were low (normal range: $1-4 \mu \mathrm{mol} / \mathrm{L}$ and
1.8-6.2 nmol/L, respectively). Steroid supplementation with hydrocortisone and fludrocortisone resulted in rapid improvement of his clinical condition.

Computed tomography (CT) scan of the abdomen revealed small noncalcified adrenal glands. The chest $x$-ray was normal, and cultures of bronchial fluid were negative. There was no evidence of tuberculosis, antiadrenocortical antibodies were negative, and very-longchain fatty acids were normal.

Physical reexamination revealed sparse facial, thoracic, and pubic hair (Tanner stage 3 ) and a gynecoid distribution of subcutaneous fat. There was no gynecomastia. Penile length was normal, but testicular volume was low ( $6 \mathrm{~mL}$ bilaterally). The patient disclosed that puberty had occurred at the age of approximately 16. He described impaired libido and infrequent erections, but he had not sought treatment for these symptoms and was able to have sexual intercourse. Testosterone concentration measured on several occasions ranged from $5.8 \mathrm{nmol} / \mathrm{L}$ to $8.4 \mathrm{nmol} / \mathrm{L}$ (normal range: $12-40 \mathrm{nmol} / \mathrm{L}$ ). Basal serum FSH and
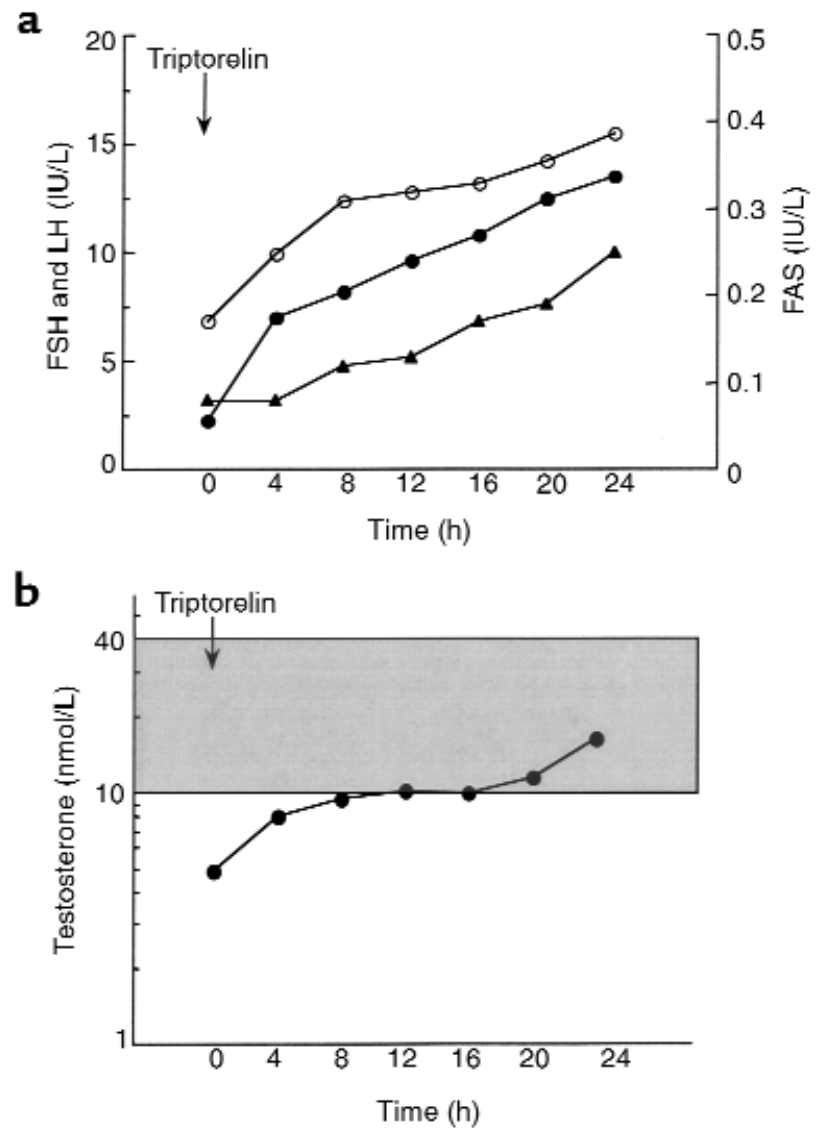

Figure 2

Response of the gonadotropic axis to GnRH analogue injection. (a) Serum FSH (open circles), LH (filled circles), and FAS (closed triangles) concentrations measured at 4-hour intervals for 24 hours after injection of the $\mathrm{GnRH}$ analogue agonist triptorelin. (b) Serum testosterone measured at 4-hour intervals for 24 hours after injection of the $\mathrm{GnRH}$ analogue agonist triptorelin. Note the logarithmic scale. The shaded area indicates the normal range of testosterone values in adult men. 


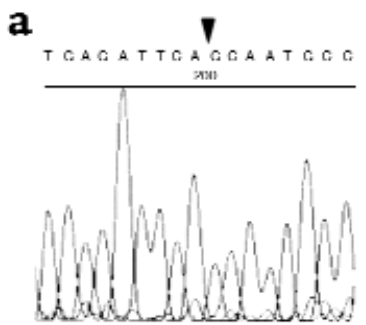

Patient
Control

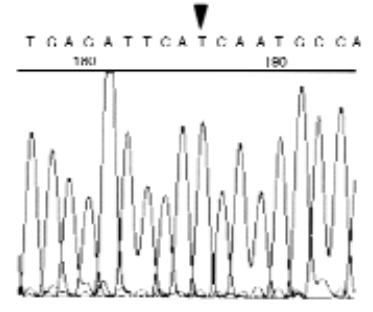

b

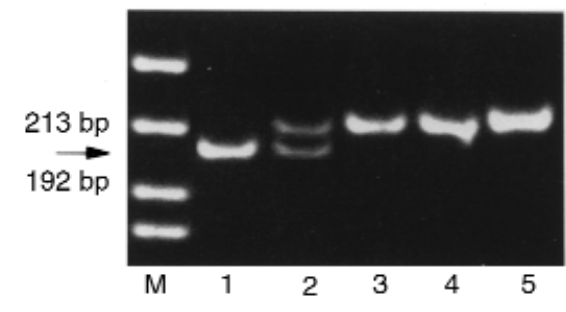

\section{Figure 3}

Identification of the DAX1 missense mutation. (a) Chromatogram showing the 1439S missense mutation in exon 2 of DAX1. A guanine is present at nucleotide position 1316 in the patient (arrow), whereas a thymine is present at the equivalent position in a genomic sequence from a control subject. (b) The thymine-to-guanine nucleotide change creates a novel BsrDI site. PCR products from the patient, his mother, his normal brother, his father, and a normal control were digested with this restriction enzyme (lanes 1-5, respectively). The mutated fragment, characterized by a band 13 bp shorter than the wild-type fragment, is present in the patient and his mother (arrows).

$\mathrm{LH}$ concentrations were $2.9 \mathrm{IU} / \mathrm{L}$ and $2.6 \mathrm{IU} / \mathrm{L}$, respectively (normal range: 1-5 IU/L), and increased to 4.6 $\mathrm{IU} / \mathrm{L}$ and $8.8 \mathrm{IU} / \mathrm{L}$ after GnRH stimulation $(50 \mu \mathrm{g}$ intravenous gonadorelin; Ferring, Gentilly, France). After human chorionic gonadotropin (hCG) stimulation (1,500 U intramuscularly daily for 3 days), serum testosterone increased from $8.0 \mathrm{nmol} / \mathrm{L}$ to 27.5 $\mathrm{nmol} / \mathrm{L}$. After 5 days of pulsatile administration of GnRH (10 $\mu \mathrm{g}$ intravenous gonadorelin every 2 hours using a computerized portable infusion pump), serum testosterone increased from $5.8 \mathrm{nmol} / \mathrm{L}$ to $12.2 \mathrm{nmol} / \mathrm{L}$ and reached the normal range for adults. Serum basal FSH and LH concentrations at that time were $6.4 \mathrm{IU} / \mathrm{L}$ and $5.3 \mathrm{IU} / \mathrm{L}$, respectively, and increased to $7.0 \mathrm{IU} / \mathrm{L}$ and $8.5 \mathrm{IU} / \mathrm{L}$ after a subsequent stimulation test using $50 \mu \mathrm{g}$ of intravenous GnRH. Serum prolactin, growth hormone, and thyroid function tests were normal. The karyotype was XY. Olfactory tests, high-resolution CT scanning and MRI of the pituitary gland, and serum ferritin concentration were all normal.

Semen analysis revealed severe oligospermia (semen volume: $2.5 \mathrm{~mL}$; sperm count: $8.5 \times 10^{6}$ per $\mathrm{mL}$; motility: 30\%; abnormal forms: 52\%). After 10 months of treatment using intramuscular exogenous gonadotropins (hCG; 5,000 IU twice weekly) and human menopausal gonadotropin (hMG; 150 IU twice weekly), his serum testosterone concentration increased to $29 \mathrm{nmol} / \mathrm{L}$ (normal range: 12-32 $\mathrm{nmol} / \mathrm{L})$. However, semen characteristics remained unchanged (semen volume: $5 \mathrm{~mL}$; sperm count: $6.0 \times$ $10^{6}$ per mL; motility: $35 \%$; abnormal forms: $56 \%$ ).

The patient was reevaluated at age 42 while being treated with hydrocortisone $(35 \mathrm{mg} / \mathrm{d})$, fludrocortisone $(100 \mu \mathrm{g} / \mathrm{d})$, and depot testosterone enanthate $(250 \mathrm{mg}$ intramuscularly every 3 weeks). Investigations of the pituitary-gonadal axis were performed 2 months after withdrawal of testosterone therapy. At that time, serum testosterone $(4.9 \mathrm{nmol} / \mathrm{L})$ and free testosterone $(27$ $\mathrm{pmol} / \mathrm{L}$ ) concentrations were low (normal range: 10-40 $\mathrm{nmol} / \mathrm{L}$ and $60-140 \mathrm{pmol} / \mathrm{L}$, respectively). Basal serum FSH and $\mathrm{LH}$ concentrations were $6.9 \mathrm{IU} / \mathrm{L}$ and 2.0 IU/L, respectively (normal range: 1-6 IU/L). Serum inhibin B was dramatically decreased $(7 \mathrm{pg} / \mathrm{mL}$; normal range: $105-165 \mathrm{pg} / \mathrm{mL}$ ). LH and FAS pulsatility was evaluated by serum sampling at 10 -minute intervals for 6 hours (Figure 1). The mean \pm SE serum LH and FAS concentrations were $2.0 \pm 0.1 \mathrm{IU} / \mathrm{L}$ and $0.10 \pm 0.02$ $\mathrm{IU} / \mathrm{L}$, respectively. Computer algorithms detected $3 \mathrm{LH}$ pulses and 4 FAS pulses of small amplitude $(0.3 \pm 0.1$ $\mathrm{IU} / \mathrm{L}$ and $0.2 \pm 0.2 \mathrm{IU} / \mathrm{L}$, respectively). Although the number of pulses was normal (19), the secretory patterns were erratic, and only $1 \mathrm{LH}$ pulse and FAS pulse were coincident $(20,21)$. Administration of the GnRH analogue agonist triptorelin/decapeptyl (Ipsen Biotech, Paris, France) induced a dramatic and progressive increase in FSH, LH, FAS, and testosterone concentrations for 24 hours (from $6.8 \mathrm{IU} / \mathrm{L}$ to $15.5 \mathrm{IU} / \mathrm{L} ; 2.2 \mathrm{IU} / \mathrm{L}$ to $13.5 \mathrm{IU} / \mathrm{L}, 0.08 \mathrm{IU} / \mathrm{L}$ to $0.25 \mathrm{IU} / \mathrm{L}$, and $4.9 \mathrm{nmol} / \mathrm{L}$ to $16.4 \mathrm{nmol} / \mathrm{L}$, respectively) (Figure 2, a and b). The hypothesis of a mutation in DAX1 was raised, and genetic analysis was performed.

There was no family history of note. The brother of the propositus was normal on clinical examination at the age of 38 . His testosterone concentration and cortisol response to cosyntropin were normal.

Mutation analysis. DNA sequencing of the human GnRH receptor gene revealed no abnormality. Direct sequencing of DAX1 revealed a thymine-to-guanine substitution at nucleotide 1316 in exon 2 (Figure 3a), which results in an isoleucine-to-serine missense mutation in codon 439 of DAX-1 (I439S). This thymine-toguanine substitution creates a novel BsrDI site, which was used to confirm the mutation in an independent PCR reaction from the patient's DNA. The BsrDI digestion pattern of PCR products from DNA samples of the family showed that the mother is heterozygous for the mutation, whereas the father and the unaffected brother have the normal allele (Figure 3b).

Transient gene expression studies. A schematic representation of the DAX-1 mutants studied is shown in Figure 4a. Fusion proteins containing the DAX-1 LBD linked to a GAL4 DBD were used to study the effect of DAX- 1 and its mutants on basal transcriptional activity of the UAS-TK109luc reporter (Figure 4b). Transient expression of wild-type DAX-1 produced marked repression (86\%) of basal transcription. This repression was reduced to approximately $50 \%$ with the 
a

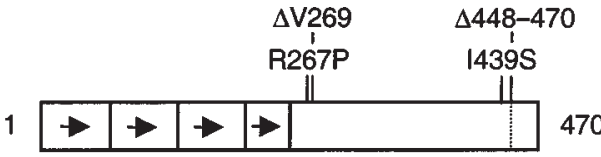

b Basal transcriptional activity

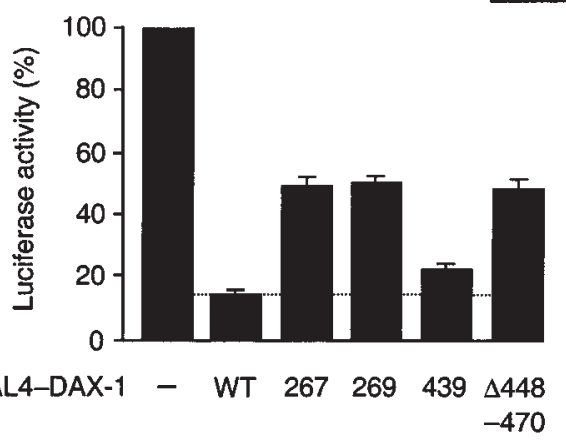

c

SF-1 mediated transactivation
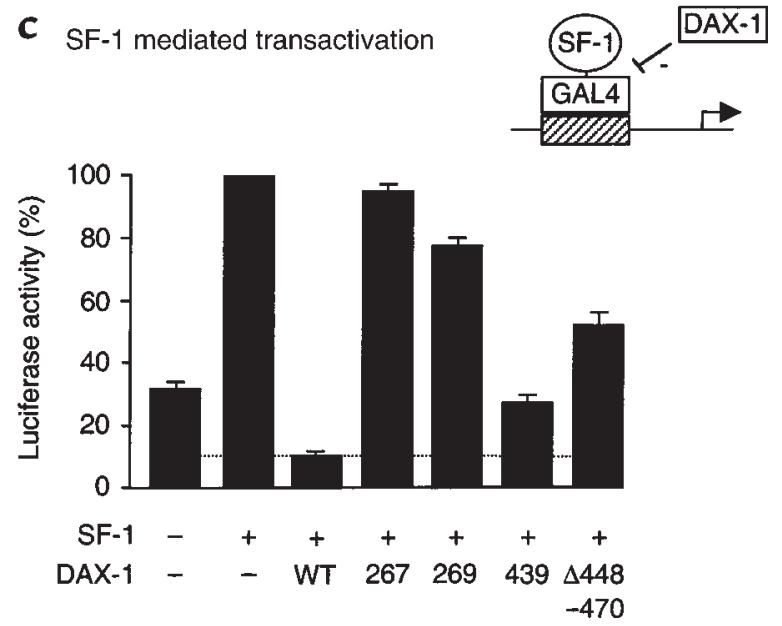

Figure 4

Functional effects of the I439S DAX-1 mutant. (a) Schematic representation of the DAX-1 mutant constructs studied. (b) The effect of wild-type DAX-1 and its mutants on basal transcriptional activity was studied using $25 \mathrm{ng}$ of a pBIND vector containing the putative LBD (207-470) of DAX-1 fused to the GAL4 DBD, and $500 \mathrm{ng}$ of a UAS-TK109luc reporter. Transient transfection studies were performed in triplicate using human tsa201 embryonic kidney cells. The mean of each triplicate reaction was expressed as a percentage of the empty vector (-) control for that study. The results represent the mean \pm SEM from at least 6 independent triplicate experiments. (c) The effect of DAX-1 and its mutants on SF-1-mediated transactivation. Transfections were performed as above, using $25 \mathrm{ng}$ of a PBINDGAL4 fusion protein containing the activation domain of SF1 (FIZF1) (residues 133-461), 50 ng PCMX-DAX1 expression vector containing the full-length wild-type or mutant cDNA, and 500 ng of a UAS-TK109luc reporter. WT, wild type.

R267P, $\Delta$ V269, and $\Delta 448-470$ mutants, consistent with previous studies (6). The I439S mutant repressed basal transcription to an intermediate degree $(77 \%)$
(I439S vs. wild type, $P<0.005$ [paired $t$ test]; I439S vs. other mutants, $P<0.0005$ [ANOVA]).

Transient expression of a GAL4-SF-1 fusion protein produced greater than 3-fold stimulation of the UASTK109luc reporter, when compared with GAL4 DBD alone (Figure 4c). Wild-type DAX-1 was a potent repressor of this SF-1-mediated transactivation (87\%), as reported previously (6). DAX-1 repression was reduced significantly when the R267P, $\Delta$ V269, and $\Delta 448-470$ mutants were cotransfected as controls $(7-49 \%)$. The I439S mutant again showed partial loss of repression (74\%) (I439S vs. wild type, $P<0.005$; I439S vs. other mutants, $P<0.000005)$.

In addition to these artificial promoters, the native $\mathrm{LH} \beta$ gene promoter was used as an assay of DAX-1 function (Figure 5). This promoter contains 2 composite SF1 /Egr-1 binding sites, which allow synergistic activation of the $L H \beta$ gene by these transcription factors (17, 22-25). Cotransfection of SF- 1 and Egr-1 produced a 22fold increase in activation, as expected. Wild-type DAX1 repressed this synergistic activation by $92 \%$, whereas repression with the R267P, $\Delta \mathrm{V} 269$, and $\Delta 448-470$ mutants ranged from $52 \%$ to $55 \%$. The I439S mutant showed partial loss of function (83\%) (I439S vs. wild type, $P<0.0001$; I439S vs. other mutants, $P<0.000005$ ).

\section{Discussion}

The discovery that mutations in the human nuclear receptor gene $D A X 1$ give rise to both $\mathrm{X}$-linked $\mathrm{AHC}$ and HHG $(1,11)$ has provided new insight into the pathogenesis of this syndrome. Here, we report the remarkable case of a man with a novel missense mutation in $D A X 1$ who presented with late-onset adrenal insufficiency, incomplete HHG, and severe oligospermia that was unresponsive to gonadotropin therapy. This case extends the clinical phenotype of DAX1 mutations to include patients with a milder disorder and delayed onset of symptoms.

The presentation of adrenal failure at 28 years of age in this patient contrasts markedly with classic cases of AHC. Boys with this condition typically develop acute adrenocortical failure shortly after birth or during early childhood, with a median age at presentation of 3 weeks $(9,13)$. Rare cases of delayed onset adrenal failure (26-30), or progressive deterioration of adrenal function after an asymptomatic period during infancy have been described (31). However, in all other cases reported to date, unequivocal symptoms of adrenal failure appeared before the age of 10 years $(13,28)$. The clinical picture described here, including the slow progression of symptoms in adulthood, absence of family history, and subclinical and undiagnosed HHG, might otherwise point to a diagnosis of autoimmune adrenal failure. Mutations in DAX1 should now be considered in the differential diagnosis of such patients.

Although the pituitary-gonadal axis may be intact in early infancy in boys with AHC $(32,33)$, failure to undergo puberty due to hypogonadotropic hypogonadism is a hallmark of this condition $(9,12,34)$. Recently, spon- 


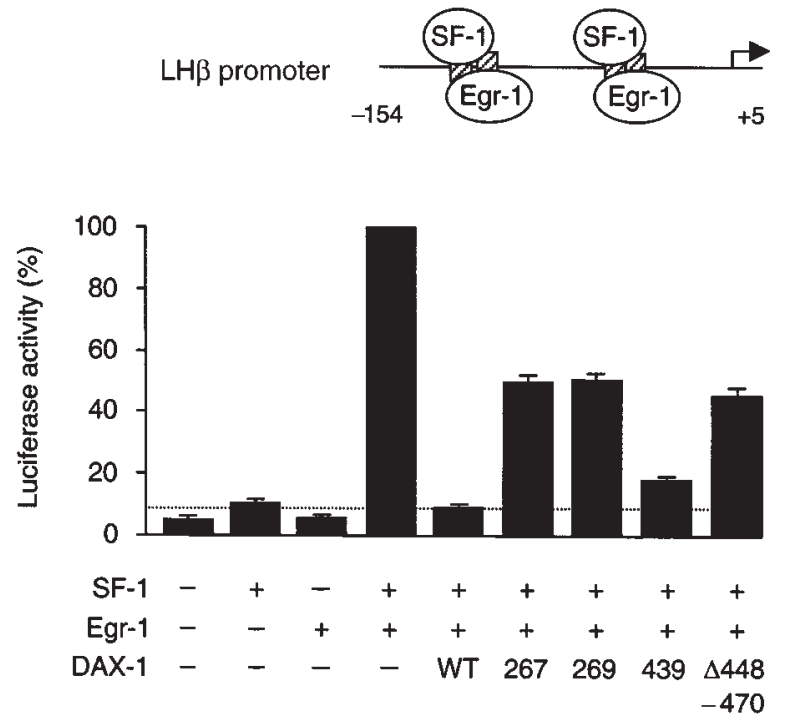

Figure 5

The effect of DAX-1 and its mutants on SF-1/Egr-1 synergistic activation of the rat $\mathrm{LH} \beta$ gene promoter. Cotransfection of human SF1 (FIZF1) (20 ng) with rat Egr1 (20 ng) produced synergistic activation of the rat LH $\beta$ gene promoter $(-154$ to +5$)(500 \mathrm{ng})$. Repression by wild-type (WT) DAX-1 (50 ng) was reduced when the R267P, $\Delta$ V269, and $\Delta 448-470$ DAX-1 mutant vectors were investigated. The I439S mutant had intermediate function.

taneous onset of puberty has been described in 3 boys with DAX1 mutations (35). Nevertheless, gonadotropin deficiency developed rapidly between 15 and 18 years in these individuals, resulting in failure of further pubertal development and low testosterone concentrations (35). The patient presented here demonstrates that DAX1 mutations may result in even milder forms of HHG. Serum testosterone concentrations were sufficient to allow significant masculinization to occur at the time of puberty, and from the patient's point of view, an acceptable level of sexual activity during adulthood.

It remains debatable whether HHG associated with $D A X 1$ mutations results from hypothalamic or pituitary dysfunction $(9,12,29,34)$. DAX-1 is expressed at both these levels (2), and recent studies suggest that they may both be involved (29). Our patient's response to pulsatile GnRH administration was less than might be expected for someone with a selective hypothalamic GnRH deficiency (e.g., Kallmann syndrome) (20, 29, 34), suggesting at least a partial pituitary component to the defect in gonadotropin production. However, most of our results favor a predominant hypothalamic defect in this case, including: (a) the normalization of serum testosterone concentration after pulsatile administration of GnRH for 5 days; (b) the dramatic and sustained increase of FSH, LH, FAS, and testosterone after administration of a GnRH agonist analogue (36-38); (c) the erratic and asynchronous pattern of pulsatile $\mathrm{LH}$ and FAS secretion, which is assumed to reflect the activity of GnRH-secreting hypothalamic neurons (20,21, 34); and (d) the low serum $\mathrm{LH} / \mathrm{FSH}$ ratio $(20,34)$.
Although HHG in this patient was incomplete, he had severe oligospermia, raising the possibility that DAX-1 may affect spermatogenesis directly. DAX- 1 is known to be expressed in Sertoli cells in rats (39), and targeted disruption of $A b c h$ (Dax1) in mice results in infertility despite apparently normal gonadotropin and adrenal steroid production (10). Indeed, progressive epithelial dysgenesis and loss of germ cells is seen after birth in these animals, consistent with a primary Sertoli cell defect $(10,40)$. Exogenous gonadotropin therapy did not correct the oligospermia in this patient, indicating that the impaired spermatogenesis results from mechanisms other than HHG. In addition, the low serum inhibin B concentration, despite a slightly elevated serum immunoreactive FSH concentration (41), provides further evidence that DAX-1 mutations cause primary defects in Sertoli cell function $(10,39)$. Taken together, these data suggest that abnormalities of spermatogenesis may also comprise part of the clinical spectrum of AHC.

The coexpression of DAX-1 with SF- 1 in the gonadal and adrenal axes $(2,3)$, and the adrenal failure seen in patients with mutations in these genes $(11,42)$, suggest that DAX-1 and SF-1 interact in a common genetic pathway. An SF-1 response element has been identified in the DAX1 promoter (4), and SF-1 activates Abch (Dax1) expression (8), while in vitro studies have consistently shown that DAX-1 actually represses SF1-mediated transactivation. Indeed, DAX-1 also inhibits transcription of SF-1 target genes involved in adrenal steroidogenesis, such as steroidogenic acute regulatory protein (StAR), P450scc, and $3 \beta$-hydroxysteroid dehydrogenase $(43,44)$. This repression is compatible with the XY sex reversal seen in association with overexpression of $A b c h / D a x 1$ in mice (45) and humans (46), where DAX-1 is thought to antagonize the actions of the testis-determination factor, SRY, in gonadal development. However, a repressor role for DAX-1 in the adrenal and reproductive axes is more difficult to understand. Nevertheless, functional studies have shown that the transcriptional silencing activity of the DAX-1 protein is localized to the carboxy terminus, corresponding to the putative $\operatorname{LBD}(6,47)$.

Diseases caused by natural mutations provide insight into the relationship between the structure and function of the proteins encoded by the mutant genes. Remarkably, all mutations associated with AHC reported to date alter the structure of the carboxy terminus of the DAX-1 protein $(1,11,13,26,27,29,32,33,35$, 48-56). The majority of these are frameshift or nonsense (stop codon) mutations that result in a truncated protein. There is no obvious correlation between the putative structural consequences of these mutations and the clinical phenotype (13). Indeed, the age at onset of adrenal insufficiency can vary within the same family, suggesting that other epigenetic or nongenetic factors influence the clinical course of AHC $(11,13,27$, 32). Analysis of phenotypes associated with missense mutations that result in single amino acid substitu- 
tions might be more helpful in revealing the relationships with genotypes and identifying important functional domains in the DAX-1 protein. About 10 different missense mutations in DAX-1 have been reported to date $(11,26,33,35,54-56)$. These are all located within the putative LBD of DAX-1, as is the novel I439S mutant described here (Figure 4a). The I439S mutation appears to represent an example of a DAX-1 mutation associated with a mild phenotype.

Functional studies were undertaken, therefore, to assess the effects of the mutant I439S DAX-1 protein on transcriptional repression. The naturally occurring DAX-1 mutations, R267P and $\Delta \mathrm{V} 269$, and a deletion mutant, $\Delta 448-470$, were included as positive controls because these are associated with clinically severe phenotypes and have been shown to reduce the inhibitory activity of DAX-1 in transient gene expression assays (5, $6,47)$. As expected, wild-type DAX-1 exerted strong repression of basal transcriptional activity (6), SF-1 mediated transcriptional activation $(5,6,47)$, and SF$1 /$ Egr-1 synergistic activation of the LH $\beta$ gene promoter $(25 ; L H \beta$ is a natural DAX-1 target gene). A significant reduction in repressor activity was seen with the R267P, $\Delta V 269$, and $\Delta 448-470$ mutants, whereas the I439S mutant had less effect on DAX-1 repressor activity. The partial loss of function seen with the I439S mutant is consistent with the mild clinical phenotype described in the patient. In addition, these data provide the first evidence that naturally occurring DAX-1 mutations affect the ability of DAX-1 to repress $L H \beta$, a natural target gene in the reproductive axis.

In conclusion, this case extends the spectrum of $\mathrm{X}$ linked AHC to include delayed onset of adrenocortical insufficiency in adulthood and subclinical HHG. The diagnosis of AHC should be considered in men with apparent idiopathic Addison's disease. After steroid replacement, careful assessment of the reproductive axis and gonadal function should be undertaken, and mutational analysis of DAX1 should be considered. Similarly, DAX1 should be considered a candidate gene in young adults presenting with mild "idiopathic" HHG. Additional studies of the spermatogenic response to gonadotropin therapy are required to confirm the probable AHC-associated infertility in these patients.

\section{Acknowledgments}

We acknowledge the assistance of M.L. Kottler who performed DNA sequence analysis of the GnRH gene. This work was performed as part of the National Cooperative Program for Infertility Research (National Institutes of Health grant U54-HD-29164 to J.L. Jameson) and was supported by General Clinical Research Center grant MO1 RR00048.

1. Zanaria, E., et al. 1994. An unusual member of the nuclear hormone receptor superfamily responsible for X-linked adrenal hypoplasia congenita. Nature. 372:635-641.

2. Guo, W., Burris, T.P., and McCabe, E.R. 1995. Expression of DAX1, the gene responsible for X-linked adrenal hypoplasia congenita and hypogonadotropic hypogonadism in the hypothalamic-pituitary-adrenal/gonadal axis. Biochem. Mol. Med. 56:8-13.

3. Parker, K.L., and Schimmer, B.P. 1997. Steroidogenic factor 1: a key determinant of endocrine development and function. Endocr. Rev. 18:361-377.

4. Burris, T.P., Guo, W., Le, T., and McCabe, E.R. 1995. Identification of a putative steroidogenic factor- 1 response element in the DAX1 promoter. Biochem. Biophys. Res. Commun. 214:576-581.

5. Crawford, P.A., Dorn, C., Sadovsky, Y., and Milbrandt, J. 1998. Nuclear receptor DAX1 recruits nuclear corepressor $\mathrm{N}-\mathrm{CoR}$ to steroidogenic factor 1. Mol. Cell. Biol. 18:2949-2956.

6. Ito, M., Yu, R., and Jameson, J.L. 1997. DAX1 inhibits SF-1-mediated transactivation via a carboxy terminal domain that is deleted in adrenal hypoplasia congenita. Mol. Cell. Biol. 17:1476-1483.

7. Nachtigal, M.W., et al. 1998. Wilm's tumor 1 and DAX1 modulate the orphan nuclear receptor SF-1 in sex-specific gene expression. Cell. 93:445-454.

8. Yu, R.N., Ito, M., and Jameson, J.L. 1998. The murine DAX1 promoter is stimulated by SF-1 (steroidogenic factor-1) and inhibited by COUP-TF (chicken ovalbumin upstream promoter-transcription factor) via a composite nuclear receptor-regulatory element. Mol. Endocrinol. 12:1010-1022.

9. Yu, R.N., Achermann, J.C., Ito, M., and Jameson, J.L. 1998. The role of DAX1 in reproduction. Trends Endocrinol. Metab. 9:169-175.

10. Yu, R.N., Ito, M., Saunders, T.L., Camper, S.A., and Jameson, J.L. 1998. Role of Ahch in gonadal development and gametogenesis. Nat. Genet. 20:353-357.

11. Muscatelli, F., et al. 1994. Mutations in the DAX1 gene give rise to both $\mathrm{X}$-linked adrenal hypoplasia congenita and hypogonadotropic hypogonadism. Nature. 372:672-676.

12. Kletter, G.B., Gorski, J.L., and Kelch, R.P. 1991. Congenital adrenal hypoplasia and isolated gonadotropin deficiency. Trends Endocrinol. Metab. 2:123-128.

13. Reutens, A.T., et al. 1999. Clinical and functional effects of mutations in the DAX1 gene in patients with adrenal hypoplasia congenita. J. Clin. Endocrinol. Metab. 84:504-511.

14. Groome, N.P., et al. 1996. Measurement of dimeric inhibin-B throughout the human menstrual cycle. J. Clin. Endocrinol. Metab. 81:1401-1405.

15. Veldhuis, J.D., and Johnson, M.L. 1986. Cluster analysis: a simple, versatile, and robust algorithm for endocrine pulse detection. Am. J. Physiol. 250:E486-E493.

16. Caron, P.J., et al. 1999. Resistance of hypogonadic patients with mutated $\mathrm{GnRH}$ receptor genes to pulsatile GnRH administration. J. Clin. Endocrinol. Metab. 84:990-996.

17. Halvorson, L.M., Ito, M., Jameson, J.L., and Chin, W.W. 1998. Steroidogenic factor- 1 and early growth response protein 1 act through two composite DNA binding sites to regulate luteinizing hormone $\beta$-subunit gene expression. J. Biol. Chem. 273:14712-14720.

18. Margolskee, R.F., McHendry-Rinde, B., and Horn, R. 1993. Panning transfected cells for electrophysiological studies. Biotechniques. 15:906-911.

19. Caron, P.J., Bennet, A.P., Plantavid, M.M., and Louvet, J.P. 1994. Luteinizing hormone secretory pattern before and after removal of Leydig cell tumor of the testis. Eur. J. Endocrinol. 131:156-159.

20. Crowley, W.F., et al. 1991. Neuroendocrine control of human reproduction in the male. Recent Prog. Horm. Res. 47:27-67.

21. Whitcomb, R.W., O’Dea, L.S., Finkelstein, J.S., Heavern, D.M., and Crowley, W.F. 1990. Utility of free alpha-subunit as an alternative neuroendocrine marker of gonadotropin-releasing hormone $(\mathrm{GnRH})$ stimulation of the gonadotroph in the human: evidence from normal and GnRH-deficient men. J. Clin. Endocrinol. Metab. 70:1654-1661.

22. Lee, S.L., et al. 1996. Luteinizing hormone deficiency and female infertility in mice lacking the transcription factor NGFI-A (Egr-1). Science. 273:1219-1221.

23. Le Dréan, Y., Liu, D., Xiong, F., and Hew, C.L. 1997. Presence of distinct cis-acting elements on gonadotropin gene promoters in diverse species dictates the selective recruitment of different transcription factors by steroidogenic factor-1. Mol. Cell. Endocrinol. 135:31-40.

24. Wolfe, M.W., and Call, G.B. 1999. Early growth response protein 1 binds to the luteinizing hormone- $\beta$ promoter and mediates gonadotropin-releasing hormone stimulated gene expression. Mol. Endocrinol. 13:752-763.

25. Dorn, C., Ou, Q., Svaren, J., Crawford, P.A., and Sadovsky, Y. 1999. Activation of luteinizing hormone $\beta$ gene by gonadotropin-releasing hormone requires the synergy of early growth response- 1 and steroidogenic factor-1. J. Biol. Chem. 274:13870-13876.

26. Nakae, J., et al. 1997. Three novel mutations and a de novo deletion mutation of the DAX1 gene in patients with X-linked adrenal hypoplasia congenita. J. Clin. Endocrinol. Metab. 82:3835-3841.

27. Yanase, T., et al. 1996. New mutations of DAX1 genes in two Japanese patients with X-linked congenital adrenal hypoplasia and hypogonadotropic hypogonadism. J. Clin. Endocrinol. Metab. 81:530-535.

28. Golden, M.P., Lippe, B.M., and Kaplan, S.A. 1977. Congenital adrenal hypoplasia and hypogonadotropic hypogonadism. Am. J. Dis. Child. 131:1117-1118 
29. Habiby, R.L., et al. 1996. Adrenal hypoplasia congenita with hypogonadotropic hypogonadism. Evidence that DAX1 mutations lead to combined hypothalamic and pituitary defects in gonadotropin production. J. Clin. Invest. 98:1055-1062.

30. Kelly, W.F., Joplin, G.F., and Pearson, G.W. 1977. Gonadotrophin deficiency and adrenocortical insufficiency in children: a new syndrome. $\mathrm{Br}$ Med. J. 2:98.

31. Sills, I.N., Voorhess, M.L., MacGillivray, M.H., and Peterson, R.E. 1983. Prolonged survival without therapy in congenital adrenal hypoplasia. Am. J. Dis. Child. 137:1186-1188.

32. Peter, M., Viemann, M., Partsch, C.J., and Sippell, W.G. 1998. Congenital adrenal hypoplasia: clinical spectrum, experience with hormonal diagnosis, and report on new point mutations of the DAX1 gene. J. Clin. Endocrinol. Metab. 83:2666-2674.

33. Takahashi, T., et al. 1997. Active hypothalamic-pituitary-gonadal axis in an infant with X-linked adrenal hypoplasia congenita. J. Pediatr. 130:485-488.

34. Seminara, S.B., Hayes, F.J., and Crowley, W.F. 1998. Gonadotropin-releasing hormone deficiency in the human (idiopathic hypogonadotropic hypogonadism and Kallman's syndrome): pathophysiological and genetic consideration. Endocr. Rev. 19:521-539.

35. Bassett, J.H.D., et al. 1999. Novel DAX1 mutations in X-linked adrenal hypoplasia congenita and hypogonadotrophic hypogonadism. Clin. Endocrinol. (Oxf.). 50:69-75.

36. Couzinet, B., Young, J., Brailly, S., Chanson, P., and Schaison, G. 1999. Functional hypothalamic amenorrhea: a partial and reversible gonadotropin deficiency of nutritional origin. Clin. Endocrinol. (Oxf.). 50:229-235.

37. Ghai, K., Cara, J.F., and Rosenfield, R.L. 1995. Gonadotropin releasing hormone agonist (Nafarelin) test to differentiate gonadotropin deficiency from constitutionally delayed puberty in teen-age boys: a clinical research center study. J. Clin. Endocrinol. Metab. 80:2980-2986.

38. Zamboni, G., Antoniazzi, F., and Tato, L. 1995. Use of the gonadotropinreleasing hormone agonist triptorelin in the diagnosis of delayed puberty in boys. J. Pediatr. 126:756-758.

39. Tamai, K.T., et al. 1996. Hormonal and developmental regulation of DAX1 expression in Sertoli cells. Mol. Endocrinol. 10:1561-1569.

40. Parker, K.L., and Schimmer, B.P. 1998. Ahch and the feminine mystique. Nat. Genet. 20:318-319.

41. Nachtigall, L.B., et al. 1996. Inhibin B secretion in males with gonadotropin-releasing hormone $(\mathrm{GnRH})$ deficiency before and during long-term $\mathrm{GnRH}$ replacement: relationship to spontaneous puberty, testicular volume and prior treatment. A clinical research center study. $J$ Clin. Endocrinol. Metab. 81:3520-3525.

42. Achermann, J.C., Ito, M., Ito, M., Hindmarsh, P.C., and Jameson, J.L.
1999. A mutation in the gene encoding steroidogenic factor- 1 causes $X Y$ sex reversal and adrenal failure in humans. Nat. Genet. 22:125-126.

43. Lalli, E., Melner, M.H., Stocco, D.M., and Sassone-Corsi, P. 1998. DAX1 blocks steroid production at multiple levels. Endocrinology. 139:4237-4243.

44. Zazopoulos, E., Lalli, E., Stocco, D.M., and Sassone-Corsi, P. 1997. DNA binding and transcriptional repression by DAX 1 blocks steroidogenesis. Nature. 390:311-315.

45. Swain, A., Narvaez, V., Burgoyne, P., Camerino, G., and Lovell-Badge, R. 1998. DAX1 antagonizes Sry action in mammalian sex determination. Nature. 391:761-767.

46. Bardoni, B., et al. 1994. A dosage sensitive locus at chromosome Xp21 is involved in male to female sex reversal. Nat. Genet. 7:497-501.

47. Lalli, E., et al. 1997. A transcriptional silencing domain in DAX1 whose mutation causes adrenal hypoplasia congenita. Mol. Endocrinol. 11:1950-1960.

48. Guo, W., et al. 1995. Diagnosis of X-linked adrenal hypoplasia congenita by mutation analysis of the DAX1 gene. JAMA. 274:324-330.

49. Guo, W., et al. 1996. Genomic sequence of the DAX1 gene: an orphan nuclear receptor responsible for the X-linked adrenal hypoplasia congenita and hypogonadotropic hypogonadism. J. Clin. Endocrinol. Metab. 81:2481-2486.

50. Hamaguchi, K., et al. 1998. Novel mutation of the DAX1 gene in a patient with X-linked adrenal hypoplasia congenita and hypogonadotropic hypogonadism. Am. J. Med. Genet. 76:62-66.

51. Kinoshita, E.I., et al. 1997. DAX1 gene mutations and deletions in Japanese patients with adrenal hypoplasia congenita and hypogonadotropic hypogonadism. Horm. Res. 48:29-34.

52. Meloni, A., Meloni, A., Cao, A., and Rosatelli, M.C. 1996. New frameshift mutation in the DAX1 gene in a patient with X-linked adrenal hypoplasia and hypogonadotropic hypogonadism. Hum. Mutat. 8:183-184.

53. Nakae, J., et al. 1996. Truncation at the C-terminus of the DAX1 protein impairs its biological actions in patients with X-linked adrenal hypoplasia congenita. J. Clin. Endocrinol. Metab. 81:3680-3685.

54. Schwartz, M., Blichfeldt, S., and Müller, J. 1997. X-linked adrenal hypoplasia in a large Greenlandic family. Detection of a missense mutation (N440I) in the DAX1 gene: implication for genetic counselling and carrier diagnosis. Hum. Genet. 99:83-87.

55. Zhang, Y.H., et al. 1998. DAX1 mutations map to putative structural domains in a deduced three-dimensional model. Am. J. Hum. Genet. 62:855-864.

56. Abe, S., et al. 1999. Novel missense mutation (Leu466Arg) of the DAX1 gene in a patient with X-linked congenital adrenal hypoplasia. Am.J. Med. Genet. 84:87-89. 